\title{
Stress Symptoms and Frequency of Sexual Intercourse Among Young Women
}

\author{
Kelli Stidham Hall, PhD, MS, ${ }^{* \dagger}$ Yasamin Kusunoki, PhD, MPH, ${ }^{\ddagger \neq}$ Heather Gatny, MS, ${ }^{\ddagger \ddagger}$ and \\ Jennifer Barber, $\mathrm{PhD}^{\dagger \neq \S}$ \\ *Department of Obstetrics and Gynecology, University of Michigan Health System, Ann Arbor, MI, USA; †Population \\ Studies Center, Institute for Social Research, University of Michigan, Ann Arbor, MI, USA; ¥Survey Research Center, \\ Institute for Social Research, University of Michigan, Ann Arbor, MI, USA; §Department of Sociology, University of \\ Michigan, Ann Arbor, MI, USA
}

DOI: $10.1111 /$ jsm. 12607

\section{A B S T R A C T}

Introduction. We have previously documented the relationships between stress and depression symptoms and adolescent women's nonuse and misuse of condoms and other contraceptive methods and on their unintended pregnancy rates.

Aim. Here, we examine relationships between mental health symptoms and another understudied adolescent reproductive health behavior-frequency of sexual intercourse.

Main Outcome Measure. Our outcome was weekly sexual intercourse activity.

Methods. We used panel data from a longitudinal, population-based cohort study of 992 women ages 18-20. Weekly journals measured sociodemographic, relationship, reproductive, and mental health characteristics, sexual and contraceptive behaviors, and pregnancy history. We examined 27,130 surveys from 952 women during the first study year. Predictors of weekly sexual intercourse were moderate to severe stress (Perceived Stress Scale-4) and depression (Center for Epidemiologic Studies Depression Scale-5) symptoms measured at baseline. Multilevel, mixed-effects logistic regression models estimated the relationships between stress and depression symptoms and the weekly odds of sexual intercourse while adjusting for covariate fixed effects and random woman effects.

Results. Nearly a quarter of the sample had moderate to severe stress (23\%) and depression (24\%) symptoms at baseline. Women reported sexual intercourse in 36\% of weeks. Proportions of sexually active weeks were higher among women with stress (43\%) and depression (40\%) compared with those without symptoms (35\% and 35\%, respectively; $P$ values $<0.001)$. Controlling for covariates, women with baseline stress symptoms had 1.6 times higher weekly odds of sexual intercourse compared with women without stress (adjusted odds ratio 1.6, confidence interval $[1.1,2.5] ; P=0.04)$. Depression symptoms were not associated with sexual intercourse frequency in adjusted models. Conclusions. Stress symptoms were positively associated with sexual intercourse frequency among these young women. Research and practice efforts are needed to identify effective sexual health promotion and risk-reduction strategies, including contraceptive education and counseling, in the context of mental health symptoms and unintended pregnancy. Hall KS, Kusunoki Y, Gatny H, and Barber J. Stress symptoms and frequency of sexual intercourse among young women. J Sex Med 2014;11:1982-1990.

Key Words. Stress; Mental Health; Sexual Intercourse; Unintended Pregnancy; Sexual Health

\section{Introduction}

$\mathrm{R}$ esearchers have documented the contribution of mental health conditions to adverse maternal and child health outcomes [1-5]. Depression, anxiety, stress, and related conditions, which are common among reproductive-aged women, have been linked with perinatal and postpartum sequelae, including maternal and infant morbidity and mortality, obstetrical complications, preterm 
and still birth, low birth weight, and antepartum and postpartum depression [1-5]. Less research, though, has focused on the role of mental health symptoms in a broader range of sexual and reproductive health outcomes, especially for young women. Adolescence is a transitional period of biological, psychological, and social development that is impacted by mental health, and it is a time when sexual behaviors and reproductive outcomes like unintended pregnancy have significant implications for women's health and life trajectories [6]. Thus, relationships between common mental health symptoms, unintended pregnancy, and the pathways to unintended pregnancy warrant attention but have been understudied in adolescent sexual and reproductive health research [7-9].

There are two primary behavioral mechanisms by which mental health could influence young women's risk of unintended pregnancy: contraception and sex. First, symptoms of stress and depression may compromise a woman's ability to perform health behavioral routines and medical regimens [10-15], which has implications for effective contraceptive use. Indeed, emerging research, including our own, has identified associations between mental health and contraceptive behaviors [16-21]. In our previous analyses of data from a populationbased longitudinal cohort study of nearly 1,000 adolescent women, we reported the effects of stress and depression symptoms on elevated rates of unintended pregnancy and nonuse and inconsistent use of condoms and other effective methods of contraceptive (e.g., hormonal and long-acting methods) $[9,16,17]$.

Second, mental health could also influence young women's sexual behavior, including frequency of sexual intercourse, as an additional or competing pathway to unintended pregnancy. Among older populations, studies have shown that mental health and perceived well-being are positively correlated with sexual intercourse and sexual pleasure among women and men in later decades of life [22-28]. From a health promotion perspective, women with mental health symptoms could engage in sexual activity to cope with or alleviate their stress or sadness [29-33]. Alternatively, decreased motivation or excessive worry (symptoms common to depression and stress) could impede a woman's desire for sex, resulting in a negative effect on sexual interest, arousal, intercourse frequency, and then subsequent unintended pregnancy risk over time [34-36]. The relationships of depression and stress with libido and sexual dysfunction among middle- and older-aged women and men, particularly those with chronic disease, have been documented [36-40].

Studies of young women's mental health and sexual behavior have largely taken a risk-reduction approach, focusing on the links between depression and "risky" sex, including earlier age at coitarche, more sexual partners, unprotected sex, sexually transmitted infection acquisition, nonconsensual sex, and sex while under the influence of alcohol and drugs [41-45]. Little research has considered the potential negative and positive associations between mental health symptoms and frequency of sexual intercourse during adolescence, especially in the context of unintended pregnancy.

\section{Study Aim}

We investigated the relationships of stress and depression symptoms with the weekly probability of sexual intercourse among a population-based cohort of adolescent women desiring to avoid pregnancy.

\section{Methods}

\section{Sample and Design}

We have described the study sample and design in other reports $[9,16,17]$. In brief, we draw upon data from 992 young women aged 18 to 20 in a longitudinal population-based cohort study. Women were randomly sampled from a racially/ ethnically and socioeconomically diverse county in the midwestern United States between March 2008 and March 2009 using names and contact information from state driver's license and personal identification card registries. We contacted eligible women (county residents ages 18-20) by mail or in person with an invitation to participate. The University of Michigan Institutional Review Board approved this study.

Eligible women who agreed to participate were informed and provided consent and completed a 60 -minute survey with our trained interviewer. The survey interview collected sociodemographics; relationship characteristics; reproductive attitudes, beliefs and intentions; sexual and contraceptive histories; and mental health symptoms. We then invited women to participate in the 2.5 -year weekly survey study. The weekly surveys measured sexual and contraceptive behaviors, as well as pregnancy status. Surveys were completed online, or by phone if internet access was unavailable during a particular week. Participants were compensated $\$ 1$ per weekly survey with $\$ 5$ bonuses for completion of 
five consecutive on-time surveys. The baseline interview response rate was $84 \%$, and $99 \%$ agreed to participate in the longitudinal study; $79 \%$ completed 12 months or more of weekly surveys.

For this analysis, we included women who were not pregnant at baseline and who completed more than one weekly survey. We focused on the first 12 months of data given the high response rates during this time and because our mental health symptoms measures were included only at baseline. Our final sample included 952 women, contributing 27,130 journals over the first study year.

\section{Primary Predictor and Outcome Measures Baseline Mental Health Symptoms}

We have previously described our measurement of mental health symptoms [9,16,17]. Standard abbreviated stress and depression instruments were included in the baseline survey interview $[46,47]$. The Perceived Stress Scale (PSS-4) is an abbreviated scale that assesses the degree to which one appraises his or her life situations as stressful, unpredictable, uncontrollable, and overloading over the previous month [46]. Women were asked how often $(0=$ never, $1=$ almost never, $2=$ sometimes, 3 = fairly often, 4 = very often) they felt "unable to control important things in life," "confident about ability to handle personal problems," that "things were going your way," and that "difficulties were piling up so high that you could not overcome them." Positively worded items were reverse-coded. Items were summed for a total score, which could range from 0 to 16 , with higher scores indicating greater stress symptoms. We used a standard score cutoff of $\geq 9$ points on the PSS-4 to denote moderate to severe stress symptoms $[9,16,17,46]$.

The Center for Epidemiologic Studies Depression Scale-5 (CES-D-5) is an abbreviated depression scale that assesses depressive symptoms over the previous week [47]. Women were asked how often over the past 7 days they felt "like you could not shake off the blues," "depressed," "sad," that "life was not worth living," and "happy." Responses were scored on a four-point scale $(0=$ rarely or none of the time, $1=$ some or little of the time, 2 =ccasionally or moderate amount of time, $3=$ most or all of the time); the positively worded item was reverse-coded. Items were then summed for a total depression score. Scores range from 0 to 15; a higher score indicates a higher degree of symptoms. We used a standard score cutoff of $\geq 4$ points on the CES-D-5 to denote moderate to severe depression symptoms $[9,16,17,47]$.

\section{Sexual Intercourse}

In each weekly survey, women were asked whether they had sexual intercourse with any partner in the previous week, which was defined to participants as "when a man puts his penis into a woman's vagina." A week was coded 1 for sexual intercourse if a woman responded "yes" and 0 if she responded otherwise.

\section{Sociodemographic and Reproductive Background Characteristics}

Covariate selection was based upon our previous work $[9,16,17]$. At baseline and weekly, we assessed women's sociodemographic and reproductive characteristics, including age, race/ethnicity (nonHispanic white, non-Hispanic black, Hispanic, or other; black or nonblack), educational enrollment (not enrolled in school, still in high school, enrolled in 2-year program, enrolled in 4-year college, or dropped out of high school), employment status (employed or unemployed), whether they were public assistance recipients (yes or no), childhood household/family structure (lived with two biological/step parents, one parent only, or other), mother's age at first birth (less than 20 years old or 20 or more years old), frequency of religious service attendance (never, less than weekly, or at least weekly), relationship status (married, engaged, in a committed relationship, in a casual sexual relationship, or none), cohabitation status (with marital or nonmarital partner; yes or no), age at coitarche, lifetime number of sexual partners, whether they had ever had sex without using birth control, and history of pregnancy. Coefficients for baseline and time-variant versions of these covariates did not differ significantly in models for the first year of data, so we present results using baseline covariates.

\section{Statistical Analysis}

We present percentage distributions of the categorical measures of women's background characteristics, mental health symptoms, and weeks with sexual intercourse. We conducted unadjusted bivariate $\chi^{2}$-tests to compare the proportion of weeks with sexual intercourse by category for background characteristics and mental health symptoms. We used multilevel, mixed-effects, multivariable logistic regression models to further examine associations between background characteristics, mental health symptoms, and weeks with sexual intercourse. All models controlled for covariate fixed effects as well as random effects for the woman and the number of journals completed. 
We estimated the relationships of moderate to severe stress symptoms and moderate to severe depression symptoms with the weekly odds of sexual intercourse in separate models. We estimated full regression models first, followed by reduced models controlling only for significant covariates.

Covariates were considered for inclusion in regression models if their $P$ values in the bivariate models were $<0.25$. For collinear variables (e.g., reproductive history indicators), we retained only variables with the strongest effect in the final models. Results are presented as exponentiated coefficients from regression models (adjusted odds ratio $[\mathrm{aOR}]$ and $95 \%$ confidence interval [CI]). Two-tailed alphas of $P<0.05$ were considered significant. Data were analyzed using Stata 12.0 (StataCorp LP, College Station, TX, USA).

\section{Results}

\section{Characteristics of the Sample}

Sociodemographic, reproductive, and mental health background characteristics of the sample $(\mathrm{N}=952)$ are presented in Table 1 . Most women identified as being of white $(59 \%)$ or black $(31 \%)$ race/ethnicity. Over half of women were enrolled in a 2- or 4-year college (57\%). A quarter of women were receiving public assistance $(27 \%)$; half were unemployed $(50 \%)$. Nearly three-quarters of women were in some type of relationship (73\%), and $17 \%$ were cohabiting with a partner. The majority of women were sexually experienced at baseline $(77 \%)$, with $51 \%$ reporting coitarche at age 16 years or younger. Nearly half of women reported a history of sex without using birth control $(48 \%)$, and nearly one-fifth had a history of pregnancy $(22 \%)$. Finally, $23 \%$ of women reported moderate to high stress symptoms, and 24\% reported moderate to severe depression symptoms at baseline.

\section{Associations of Sexual Intercourse With Background and Mental Health Characteristics}

Women reported sexual intercourse in $36 \%$ of weeks. In the unadjusted bivariate analysis, the proportion of weeks in which sexual intercourse occurred varied significantly by all sociodemographic and reproductive background characteristics, with the exception of age ('Table 1 , all $P$ values $<0.001)$. Compared with their counterparts, more frequent sexual intercourse was noted among women who were nonblack, not enrolled
Table 1 Proportions of sexual intercourse weeks over the 12-month study period by sociodemographic characteristics and mental health symptoms

\begin{tabular}{|c|c|c|c|}
\hline & $\begin{array}{l}\text { Total } \\
\text { percentage }\end{array}$ & $\begin{array}{l}\text { Percentage of } \\
\text { weeks in } \\
\text { which sexual } \\
\text { intercourse } \\
\text { occurred }\end{array}$ & $P$ value $^{\dagger}$ \\
\hline All women ${ }^{\ddagger}$ & 100 & 36 & \\
\hline Age & & & 0.60 \\
\hline 18 years & 41 & 36 & \\
\hline 19 years & 50 & 37 & \\
\hline 20 years & 9 & 36 & \\
\hline Race/ethnicity & & & $<0.001^{\star * *}$ \\
\hline White & 59 & 38 & \\
\hline Black & 31 & 31 & \\
\hline Hispanic & 8 & 40 & \\
\hline Other & 2 & 43 & \\
\hline Educational enrollment & & & $<0.001^{\star * *}$ \\
\hline Not enrolled & 22 & 48 & \\
\hline High school & 14 & 33 & \\
\hline 2-year college & 29 & 36 & \\
\hline 4-year college & 28 & 30 & \\
\hline High school dropout & 8 & 48 & \\
\hline Employment status & & & $<0.001^{* * *}$ \\
\hline Employed & 50 & 41 & \\
\hline Unemployed & 50 & 32 & \\
\hline Receiving public assistance & & & $<0.001^{\star * *}$ \\
\hline Yes & 27 & 43 & \\
\hline No & 73 & 35 & \\
\hline Childhood family structure & & & $<0.001^{\star * *}$ \\
\hline Two parents (biological/step) & 52 & 34 & \\
\hline One parent only & 40 & 38 & \\
\hline Other & 8 & 42 & \\
\hline Mother's age at first birth & & & $<0.001^{\star * *}$ \\
\hline$<20$ years old & 37 & 42 & \\
\hline$\geq 20$ years old & 63 & 34 & \\
\hline Religious service attendance & & & $<0.001^{\star * *}$ \\
\hline Never & 22 & 42 & \\
\hline Less than weekly & 52 & 42 & \\
\hline At least weekly & 26 & 22 & \\
\hline Relationship status & & & $<0.001^{* * *}$ \\
\hline Married & 2 & 74 & \\
\hline Engaged & 7 & 69 & \\
\hline Committed relationship & 48 & 50 & \\
\hline Casual sexual relationship & 16 & 29 & \\
\hline None & 27 & 12 & \\
\hline Cohabiting status & & & $<0.001^{\star * *}$ \\
\hline Cohabiting & 17 & 69 & \\
\hline Not cohabiting & 83 & 31 & \\
\hline Lifetime number of sexual partners & & & $<0.001^{\star \star *}$ \\
\hline 0 & 23 & 5 & \\
\hline 1 & 17 & 46 & \\
\hline 2 & 13 & 45 & \\
\hline$\geq 3$ & 46 & 53 & \\
\hline Age at coitarche & & & $<0.001^{* * *}$ \\
\hline$\leq 16$ years & 51 & 52 & \\
\hline$>16$ years & 49 & 24 & \\
\hline $\begin{array}{l}\text { Ever had sex without using } \\
\text { birth control }\end{array}$ & & & $<0.001^{\star \star *}$ \\
\hline Yes & 48 & 53 & \\
\hline No & 52 & 25 & \\
\hline History of pregnancy & & & $<0.001^{* * *}$ \\
\hline Yes & 22 & 51 & \\
\hline No & 78 & 34 & \\
\hline Moderate to severe stress ${ }^{\ddagger}$ & & & $<0.001^{\star * *}$ \\
\hline Yes ( $\geq 9$ points on PSS- 4 ) & 23 & 43 & \\
\hline No (<9 points on PSS-4) & 77 & 35 & \\
\hline Moderate to severe depression ${ }^{\ddagger}$ & & & $<0.001^{\star \star *}$ \\
\hline Yes ( $\geq 4$ points on CES-D-5) & 24 & 40 & \\
\hline No (<4 points on CES-D-5) & 76 & 35 & \\
\hline
\end{tabular}

$\mathrm{N}=952$ women $(27,130$ weekly journals $)$

All variables measured at baseline

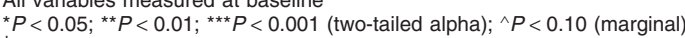

$\dagger P$ values are from unadjusted Chi-square comparing proportions across sociodemographic and reproductive characteristics and mental health symptoms.

‡Results for associations between stress and depression and sexual intercourse also similar when modeled as a four-level categorical combined mental health symptom similar when modeled as a four-level categorical combined mental health symptom
variable (no symptoms, moderate to severe stress symptoms only, moderate to severe depression symptoms only, or comorbid stress and depression symptoms) PSS-4 = Perceived Stress Scale-4; CES-D- $5=$ Center for Epidemiologic Studies Depression Scale-5 
Table 2 Effect of stress symptoms on the weekly odds of sexual intercourse

\begin{tabular}{|c|c|c|c|c|c|c|}
\hline & \multicolumn{2}{|c|}{ Model 1 (Univariate) } & \multicolumn{2}{|c|}{ Model 3 (Full) } & \multicolumn{2}{|c|}{ Model 4 (Reduced) } \\
\hline & $\mathrm{aOR}$ & $\mathrm{Cl}$ & $\mathrm{aOR}$ & $\mathrm{Cl}$ & $\mathrm{aOR}$ & $\mathrm{Cl}$ \\
\hline \multicolumn{7}{|l|}{ Moderate to severe stress ${ }^{\dagger}$} \\
\hline No (<9 points on PSS-4) & 1 & & 1 & & 1 & \\
\hline Yes ( $\geq 9$ points on PSS- 4$)$ & $1.8^{*}$ & {$[1.1,2.9]$} & $1.5^{\star}$ & {$[1.0,2.4]$} & $1.6^{*}$ & {$[1.1,2.5]$} \\
\hline \multicolumn{7}{|l|}{ Race/ethnicity } \\
\hline Nonblack & & & 1 & & 1 & \\
\hline Black & & & $0.7^{\wedge}$ & {$[0.4,1.1]$} & $0.7^{\wedge}$ & {$[0.5,1.1]$} \\
\hline \multicolumn{7}{|l|}{ Educational enrollment } \\
\hline Not enrolled/dropout & & & 1 & & 1 & \\
\hline High school & & & 0.8 & {$[0.4,1.5]$} & 0.7 & {$[0.4,1.3]$} \\
\hline 2-year college & & & 0.9 & {$[0.6,1.5]$} & 0.8 & {$[0.5,1.4]$} \\
\hline 4-year college & & & $0.6^{\wedge}$ & {$[0.4,1.0]$} & $0.5^{*}$ & {$[0.3,0.9]$} \\
\hline \multicolumn{7}{|l|}{ Employment status } \\
\hline Unemployed & & & 1 & & & \\
\hline Employed & & & 1.3 & {$[0.9,1.8]$} & & \\
\hline \multicolumn{7}{|l|}{ Receiving public assistance } \\
\hline No & & & 1 & & & \\
\hline Yes & & & $0.6^{\wedge}$ & {$[0.4,1.0]$} & & \\
\hline \multicolumn{7}{|l|}{ Childhood family structure } \\
\hline 2 parents (biological/step) & & & 1 & & & \\
\hline 1 parent only & & & 0.8 & {$[0.5,1.1]$} & & \\
\hline Other & & & 0.6 & {$[0.3,1.2]$} & & \\
\hline \multicolumn{7}{|l|}{ Religious service attendance } \\
\hline Less than weekly & & & 1 & & 1 & \\
\hline At least weekly & & & $0.5^{\star \star}$ & {$[0.3,0.8]$} & $0.4^{\star \star \star}$ & {$[0.3,0.7]$} \\
\hline \multicolumn{7}{|l|}{ Cohabitation status } \\
\hline Not cohabiting & & & 1 & & 1 & \\
\hline Cohabiting & & & $8.7^{\star \star \star}$ & {$[5.2,14.5]$} & $8.6^{\star \star \star}$ & {$[5.2,14.2]$} \\
\hline \multicolumn{7}{|l|}{ Age at coitarche } \\
\hline$>16$ years & & & 1 & & 1 & \\
\hline$\leq 16$ years & & & $6.0^{\star \star \star *}$ & {$[4.0,9.0]$} & $6.7^{\star \star \star}$ & {$[4.5,10.0]$} \\
\hline \multicolumn{7}{|l|}{ History of pregnancy } \\
\hline No & & & 1 & & & \\
\hline Yes & & & 1.1 & {$[0.7,1.8]$} & & \\
\hline
\end{tabular}

$\mathrm{N}=952$ women $(27,130$ weekly journals)

All variables measured at baseline

Results are adjusted odds ratios (aOR) and 95\% confidence intervals $(\mathrm{Cl})$ from univariate, full, and reduced multilevel, mixed-effects logistic regression models controlling for a random effect for the woman and number of journals completed

${ }^{\star} P<0.05 ;{ }^{\star \star} P<0.01 ;{ }^{* \star *} P<0.001$ (two-tailed alpha); ${ }^{\wedge} P<0.10$ (marginal)

tWhen modeled as a four-level categorical combined mental health symptom variable (no symptoms, moderate to severe stress symptoms only, moderate to severe depression symptoms only, comorbid stress and depression symptoms), point estimates for stress and comorbid stress and depression are similar to those shown for stress

PSS-4 = Perceived Stress Scale-4

in/dropped out of school, employed, receiving public assistance, from a nontraditional childhood family structure (one parent only or other), born to a teen mother, infrequently or never attending religious services, and married, engaged, or cohabiting, as well as women with more lifetime sexual partners, early age at coitarche, history of sex without using birth control, and history of pregnancy.

The frequency of sexual intercourse was also higher among women with moderate to severe stress (43\%) and depression (40\%) symptoms compared with women without such symptoms $(35 \%$ and $35 \%$, respectively; $P$ values $<0.001$ ) (Table 1 ).

In multivariable models controlling for random woman effects and covariate fixed effects (Tables 2 and 3), women with moderate to severe stress symptoms had 1.6 times higher weekly odds of sexual intercourse compared with those without stress symptoms (aOR 1.6, 95\% CI [1.1, 2.5]; $P=0.04)$. Depression symptoms did not predict sexual intercourse in adjusted models.

Other predictors of sexual intercourse included race/ethnicity, educational enrollment, receipt of public assistance, religious service attendance, cohabitation, and age at coitarche (Tables 2 and 3).

\section{Discussion}

Positive associations between sexual intercourse and different psychological and physiological health indicators, including biological markers of stress response, have been documented [22-28]. In a comprehensive review of the literature on the 
Table 3 Effect of depression symptoms on the weekly odds of sexual intercourse

\begin{tabular}{|c|c|c|c|c|c|c|}
\hline & \multicolumn{2}{|c|}{ Model 1 (Univariate) } & \multicolumn{2}{|c|}{ Model 3 (Full) } & \multicolumn{2}{|c|}{ Model 4 (Reduced) } \\
\hline & $\mathrm{aOR}$ & $\mathrm{Cl}$ & $\mathrm{aOR}$ & $\mathrm{Cl}$ & aOR & $\mathrm{Cl}$ \\
\hline \multicolumn{7}{|l|}{ Moderate to severe depression } \\
\hline No $(<4$ points on CES-D-5) & 1 & & 1 & & 1 & \\
\hline Yes ( $\geq 4$ points on CES-D-5) & 1.4 & {$[0.9,2.2]$} & 1.0 & {$[0.7,1.6]$} & 1.0 & {$[0.7,1.5]$} \\
\hline \multicolumn{7}{|l|}{ Race/ethnicity } \\
\hline Nonblack & & & 1 & & 1 & \\
\hline Black & & & $0.7^{\wedge}$ & {$[0.4,1.1]$} & $0.6^{*}$ & {$[0.4,0.9]$} \\
\hline \multicolumn{7}{|l|}{ Educational enrollment } \\
\hline Not enrolled/dropout & & & 1 & & 1 & \\
\hline High school & & & 0.8 & {$[0.4,1.4]$} & 0.8 & {$[0.4,1.4]$} \\
\hline 2-year college & & & 0.9 & {$[0.6,1.5]$} & 0.9 & {$[0.6,1.5]$} \\
\hline 4-year college & & & $0.6^{\wedge}$ & {$[0.4,1.0]$} & $0.6^{\wedge}$ & {$[0.4,1.1]$} \\
\hline \multicolumn{7}{|l|}{ Employment status } \\
\hline Unemployed & & & 1 & & & \\
\hline Employed & & & 1.2 & {$[0.8,1.8]$} & & \\
\hline \multicolumn{7}{|l|}{ Receiving public assistance } \\
\hline No & & & 1 & & 1 & \\
\hline Yes & & & $0.6^{*}$ & {$[0.4,1.0]$} & $0.6^{*}$ & {$[0.4,0.9]$} \\
\hline \multicolumn{7}{|l|}{ Childhood family structure } \\
\hline Two parents (biological/step) & & & 1 & & & \\
\hline One parent only & & & 0.8 & {$[0.5,1.2]$} & & \\
\hline Other & & & 0.7 & {$[0.3,1.3]$} & & \\
\hline \multicolumn{7}{|l|}{ Religious service attendance } \\
\hline Less than weekly & & & 1 & & 1 & \\
\hline At least weekly & & & $0.5^{\star \star}$ & {$[0.3,0.8]$} & $0.5^{\star \star}$ & {$[0.3,0.8]$} \\
\hline \multicolumn{7}{|l|}{ Cohabitation status } \\
\hline Not cohabiting & & & 1 & & 1 & \\
\hline Cohabiting & & & $8.3^{\star \star \star}$ & {$[5.0,13.9]$} & $8.4^{\star \star \star}$ & {$[5.0,14.0]$} \\
\hline \multicolumn{7}{|l|}{ Age at coitarche } \\
\hline$>16$ years & & & 1 & & 1 & \\
\hline$\leq 16$ years & & & $6.3^{\star \star \star}$ & {$[4.2,9.5]$} & $6.4^{\star \star \star}$ & {$[4.3,9.5]$} \\
\hline \multicolumn{7}{|l|}{ History of pregnancy } \\
\hline No & & & 1 & & & \\
\hline Yes & & & 1.1 & {$[0.7,1.8]$} & & \\
\hline
\end{tabular}

$\mathrm{N}=952$ women $(27,130$ weekly journals)

All variables measured at baseline

Results are adjusted odds ratios (aOR) and 95\% confidence intervals ( $\mathrm{Cl}$ ) from univariate, full, and reduced multilevel, mixed-effects logistic regression models controlling for a random effect for the woman and number of journals completed

${ }^{\star} P<0.05$; ${ }^{\star \star} P<0.01 ;{ }^{* \star *} P<0.001$ (two-tailed alpha); ${ }^{\wedge} P<0.10$ (marginal)

CES-D-5 = Center for Epidemiologic Studies Depression Scale-5

health benefits of sex, Brody et al. found that frequent and regular sexual intercourse was correlated with greater mental health well-being, fewer depressive symptoms, better heart rate variability, and lower blood pressure, among other outcomes [24]. Most studies, including those in the literature review, though, have focused on sexual behaviors of middle- and older-aged adults. Our findings contribute to this literature by pointing to the link between adolescents' mental health and sexual activity. The 1.6-fold higher odds of sexual intercourse experienced by young women in our study with moderate to severe stress symptoms at baseline (compared with those without symptoms) appear to be nontrivial, given that the estimate represents an effect of stress on sex for each week over the 1-year study period. Unfortunately, the larger study from which data were drawn did not include time-variant measures of mental health symptoms following sexual activity or even at the conclusion of the study period, which precluded us from determining whether increased frequency of sexual intercourse corresponded with improved mental health symptoms over time or vice versa-whether changes in mental health status led to changes in sexual intercourse activity. Additional research is needed to test whether more frequent sexual intercourse among adolescents with stress symptoms may be a healthpromotion behavior used to reduce stress and improve psychological well-being.

The majority of research on adolescents' mental health and sexual behaviors has largely focused on a few outcomes (e.g., early coitarche, multiple sexual partners), used specific study samples/ settings (e.g., sexual minorities, homeless youth, HIV/AIDS) or been limited by cross-sectional and retrospective designs [41-45,48-50]. There is a dearth of research to support our findings and 
provide further understanding of interrelationships between mental health and frequency of sexual intercourse, especially among healthy adolescents in population-based contexts. In Sales et al.'s recent HIV intervention study of 304 African American adolescent women, depressive symptoms were positively associated with higher sexual arousability, which was related to the frequency of vaginal sex in the past 6 months among their clinic-based sample [51]. Unlike the Sales study, we did not find a relationship between depression symptoms and sexual frequency, nor did the larger study from which our data were drawn include other important measures of sexual health, such as masturbation, sexual satisfaction, pleasure, arousability, and the like. All of these indicators would be critical to consider in future studies of mental and sexual health given that they may mediate or help explain relationships between stress and frequency of intercourse. Nonetheless, ours is the first study of which we are aware to extend the question beyond depression and begin to highlight the role of stress in sexual experiences for young women.

Health behavior research in other areas has suggested that young women often engage in risky behaviors to cope with or alleviate stress and mental distress, including substance use, binge eating, and even sex while intoxicated [32,33,41-45]. Frequent sexual intercourse (i.e., increased exposure) among adolescent women with stress symptoms (which we have described here) may contribute to increased risk of unintended pregnancy and sexually transmitted infections if condoms and other contraceptive methods are not used or are misused (which we have described elsewhere $[9,16,17])$. Research is warranted to evaluate the other health-related behaviors - both sexual and nonsexual - that young women may use to cope with stress and depression symptoms and other mental health issues and to determine their contributions to sexual and reproductive outcomes.

Additionally, the reciprocal relationshipwhereby a broader range of sexual behaviors and health, including intercourse, masturbation, sexual satisfaction, and the like influences mental and physical health, especially during adolescence and young adulthood—also deserves attention. Perhaps this would be particularly relevant for research on mental health and contraceptive use. For instance, the Sales et al. study found a positive association between higher depressive symptoms, sexuality constructs including arousability, and the number of unprotected vaginal intercourse encounters [51].
Similarly, findings from our own previous work on mental health and contraceptive behaviors using these same data suggested that our women with baseline stress and depression symptoms experienced an increased risk of contraceptive nonuse and inconsistent use over one year (including both condoms and hormonal contraceptive methods) [16-21]. In both our current and previous analyses, mental health measurement was limited to baseline abbreviated assessments of stress and depression, which prevented an adequate examination of dynamic relationships between mental health and sexual activity and the potential effects of sexual intercourse frequency on stress and depression symptoms over time. Collectively, findings from this small body of research point to the need for additional longitudinal studies that can illuminate corresponding trajectories of mental and sexual and reproductive health outcomes across adolescence and young adulthood.

Several other important limitations of our study are noteworthy. Our standard abbreviated screening instruments used to measure stress and depression assessed mental health symptoms at only baseline and were not comprehensive or diagnostic. Other important psychological and biological health measures, such as biomarkers of stress or sexually transmitted infection outcomes, were not assessed, nor were other behavioral and psychosocial indicators of "coping," such as substance use, eating disorder symptoms, diet, exercise and sleep patterns, or social support, which have been linked with sexual behavior [6,29,32]. Moreover, relationship dynamics were not the focus here but potentially played an important role in associations between stress and sexual intercourse. Intimate partner violence, for instance, is highly correlated with adverse sexual experiences and with negative mental and physical health outcomes, while stable relationships with supportive partners may have a positive effect on both mental and sexual health $[29,30,32,52,53]$. All of these factors would be relevant for future investigations of the interrelationships between mental and sexual and reproductive health among young women.

Despite limitations, our study contributes new information on understudied, intersecting dimensions of women's health and well-being during adolescence. Specifically, commonly experienced stress symptoms appear to influence young women's sexual behaviors and reproductive outcomes. Our findings have implications for sexual and reproductive health providers, especially those who care for women with mental health consider- 
ations. Young women who wish to avoid unintended pregnancy and sexually transmitted infections should be educated and counseled on the risks of increased sexual activity when unprotected, which can contribute to both adverse reproductive health outcomes and mental distress [6]. Young women who present clinically with elevated mental health symptoms, such as those with positive screens on standard stress or depression instruments, may benefit from tailored clinical approaches that help them to understand the importance of their mental health status for contraceptive decision-making and behavior and then equip them with the knowledge and self-efficacy to choose and successfully use effective contraceptive methods, including dual method use. Finally, while additional research is needed to understand whether and how young women's sexual activity shapes their mental and physical health outcomes, clinical and public health strategies can continue to promote (safe and consensual) sex as an important and normal part of health and well-being for all women, including adolescents [54,55].

\section{Acknowledgments}

This work was supported by a National Institute of Child Health and Human Development (NICHD) Building Interdisciplinary Research Careers in Women's Health K-12 Career Development Award \#K12HD001438 (Hall, PI Johnson), by NICHD grant \#R01-HDHD050329 (Barber), by NICHD grant \#R24HD041028 (Smock), and by NICHD grant \# R21-DA024186 (Axinn).

Corresponding Author: Kelli Stidham Hall, PhD, MS, Department of Obstetrics and Gynecology, University of Michigan, L4000 Women's Hospital, 1500 East Medical Center Dr., Ann Arbor, MI 48109, USA. Tel: 734-232-1818; Fax: 734-647-9727; E-mail: hkelli @umich.edu

Conflict of Interest: The authors report no conflicts of interest.

\section{Statement of Authorship}

Category I

(a) Conception and Design

Kelli Stidham Hall; Marsha K. Guess

(b) Acquisition of Data

Kelli Stidham Hall; Yasamin Kusunoki; Heather Gatny; Jennifer Barber

(c) Analysis and Interpretation of Data

Kelli Stidham Hall; Yasamin Kusunoki; Heather Gatny; Jennifer Barber

\section{Category 2}

(a) Drafting the Article

Kelli Stidham Hall

(b) Revising It for Intellectual Content

Kelli Stidham Hall; Yasamin Kusunoki; Heather Gatny; Jennifer Barber

\section{Category 3}

(a) Final Approval of the Completed Article Kelli Stidham Hall; Yasamin Kusunoki; Heather Gatny; Jennifer Barber

\section{References}

1 Grote NK, Bridge JA, Gavin AR, Melville JL, Iyengar S, Katon WJ. A meta-analysis of depression during pregnancy and the risk of pre-term birth, low birth weight and intrauterine growth restriction. Arch Gen Psychiatry 2010;67:1012-24.

2 Alder J, Fink N, Bitzer J, Hosli I, Holzgreve W. Depression and anxiety during pregnancy: A risk factor for obstetric, fetal and neonatal outcome? A critical review of the literature. J Matern Fetal Neonatal Med 2007;20:189-209.

3 Williams KE, Marsh WK, Rasgon NL. Mood disorders and fertility in women: A critical review of the literature and implications for future research. Hum Reprod Update 2007;13:60716.

4 Lancaster CA, Gold KJ, Flynn HA, Yoo H, Marcus SM, Davis MM. Risk factors for depressive symptoms during pregnancy: A systematic review. Am J Obstet Gynecol 2010;205:5-14.

5 Gavin NI, Gaynes BN, Lohr KN, Meltzer-Brody S, Gartlehner G, Swinson T. Perinatal depression: A systematic review of prevalence and incidence. Obstet Gynecol 2005;106: 1071-83.

6 McNealy C, Blanchard J. Teen stress. In: The teen years explained: a guide to healthy adolescent development. Baltimore, MD: Center for Adolescent Health, Johns Hopkins Bloomberg School of Public Health; 2010. Available at: http:// www.jhsph.edu/research/centers-and-institutes/center-for -adolescent-health/_includes/Teen_Stress_Standalone.pdf (accessed September 13, 2013).

7 Takahashi S, Tsuchiya KJ, Matsumoto K, Suzuki K, Mori N, Takei N. Psychosocial determinants of mistimed and unwanted pregnancy: The Hamamatsu Birth Cohort Study. Matern Child Health J 2012;16:947-55.

8 Kessler RC, Berglund PA, Foster CL, Saunders WB, Stang PE, Walters EE. Social consequences of psychiatric disorders, II: Teenage parenthood. Am J Psychiatry 1997;154:1405-11.

9 Hall KS, Kusunoki Y, Gatny H, Barber J. Unintended pregnancy risk among young women with psychological stress and depression symptoms. Soc Sci Med 2014;100:62-71.

10 Yuen KSL, Lee TMC. Could mood state affect risk-taking decisions? J Affect Disord 2003;75:11-8.

11 Ruscher S, de Wit R, Mazimanian D. Psychiatric patients' attitudes about medication and factors affecting noncompliance. Psychiatr Serv 1997;48:82-5.

12 Patel MS, David AS. Medication adherence: Predictive factors and enhancement strategies. Psychiatry 2004;3:41-4.

13 Calev A. Assessment of neuropsychological functions in psychotic disorders. Washington DC: American Psychiatric Press; 1999.

14 Hartley CA, Phelps EA. Anxiety and decision-making. Biol Psychiatry 2012;72:113-8.

15 Alvy LM, McKirnan DJ, Mansergh G, Koblin B, Colfax GN, Flores SA, Hudson S; Project MIX Study Group. Depression 
is associated with sexual risk among men who have sex with men, but is mediated by cognitive escape and self-efficacy. AIDS Behav 2011;15:1171-9.

16 Hall K, Moreau C, Trussell J, Barber J. Role of young women's depression and stress symptoms in their weekly use and nonuse of contraceptive methods. J Adolesc Health 2013;53:241-8.

17 Hall K, Moreau C, Trussell J, Barber J. Young women's consistency of contraceptive use-Do depression and stress matter? Contraception 2013;88:641-9.

18 Hall K, Reame N, O'Connell K, Rickert V, Weshoff C. Influence of depressed mood and psychological stress symptoms on perceived oral contraceptive side effects and discontinuation in young minority women. Contraception 2012;86:518-25.

19 Garbers S, Correa N, Tobier N, Blust S, Chiasson MA. Associations between symptoms of depression and contraceptive method choices among low-income women at urban reproductive health centers. Matern Child Health J 2010;14:102-9.

20 Zink TM, Shireman TI, Ho M, Buchanan T. High-risk teen compliance with prescription contraception: An analysis of Ohio Medicaid Claims. J Pediatr Adolesc Gynecol 2002;15: $15-21$.

21 Steinberg JR, Tschann JM, Henderson JT, Drey EA, Steinauer JE, Harper CC. Psychological distress and post-abortion contraceptive choice at an urban clinic. Contraception 2013;88: $717-24$.

22 Lindau ST, Schumm LP, Laumann EO, Levinson W, O'Muircheartaigh CA, Waite LJ. A study of sexuality and health among older adults in the United States. NEJM 2007; 357:762-74.

23 Addis IB, Van Den Eeden SK, Wassel-Fyr CL, Vittinghoff E, Brown JS, Thom DH; Reproductive Risk Factors for Incontinence Study at Kaiser Group. Sexual activity and function in middle-aged and older women. Obstet Gynecol 2006;107: 755-64.

24 Brody S. The relative health benefits of different sexual activities. J Sex Med 2010;7:1336-61.

25 Brody S, Preut R. Vaginal intercourse frequency and heart rate variability. J Sex Marital Ther 2003;29:371-80.

26 Brody S, Costa RM. Satisfaction (sexual, life, relationship, mental health) is associated directly with penile-vaginal intercourse but inversely with other sexual behavior frequencies. J Sex Med 2009;6:1947-54.

27 Costa RM, Brody S. Women's relationship quality is associated with specifically penile-vaginal intercourse orgasm and frequency. J Sex Marital Ther 2007;33:319-27.

28 Reece M, Herbenick D, Schick V, Sanders SA, Dodge B, Fortenberry JD. Sexual behaviors, relationships and perceived health among adult men in the United States: Results from a national probability sample. J Sex Med 2010;7:291-304.

29 Schneiderman N, Ironson G, Siegel SD. Stress and health: Psychological, behavioral and biological determinants. Annu Rev Clin Psychol 2005;1:607-28.

30 Umberson D, Crosnoe R, Reczek C. Social relationships and health behavior across life course. Annu Rev Sociol 2010;36: $139-57$.

31 Thoits PA. Stress and health: Major findings and policy implications. J Health Soc Behav 2010;51:S41.

32 Thoits PA. Stress, coping and social support processes: Where are we? What next? J Health Soc Behav 1995;35(extra issue): $53-79$.

33 Krueger PM, Chang VW. Being poor and coping with stress: Health behaviors and the risk of death. Am J Public Health 2008;98:889-96.

34 Maner JK, Schmidt NB. The role of risk avoidance in anxiety. Behav Ther 2006;37:181-9.

35 Clery-Melin ML, Schmidt L, Lafargue G, Baup N, Fossati P, Pessiglione M. Why don't you try harder? An investigation of effort production in major depression. PLoS ONE 2011; 6(e23178):1-8

36 Hamilton LD, Mestin CM. Chronic stress and sexual function in women. J Sex Med 2013;10:2443-54.

37 Laumann EO, Paik A, Rosen RC. Sexual dysfunction in the United States: Prevalence and predictors. JAMA 1999;281: $537-44$.

38 Heiman JR. Sexual dysfunction: Overview of prevalence, etiological factors and treatments. J Sex Res 2002;39:73-8.

39 Dunn KM, Croft PR, Hackettt GI. Association of sexual problems with social, psychological and physical problems in men and women: A cross sectional population survey. J Epidemiol Community Health 1999;53:144-8.

40 Shifren JL, Monz BU, Russo PA, Segreti A, Johannes CB. Sexual problems and distress in United States women: Prevalence and correlates. Obstet Gynecol 2008;112:970-8.

41 Brooks TL, Harris SK, Thrall JS, Woods ER. Association of adolescent risk behaviors with mental health symptoms in high school students. J Adolesc Health 2002;31:240-6.

42 Lehrer JA, Shrier LA, Gortmaker S, Buka S. Depressive symptoms as longitudinal predictors of sexual risk behaviors among US middle and high school students. Pediatrics 2006;118:189200.

43 Shrier LA, Harris SK, Sternberg M, Beardslee WR. Associations of depression, self-esteem, and substance use with sexual risk among adolescents. Prev Med 2001;33:179-89.

44 Chen YW, Stiffman AR, Cheng LC, Dore P. Mental health, social environment and sexual risk behaviors of adolescent service users: A gender comparison. J Child Fam Stud 1997; 6:9-25.

45 Katon W, Richardson L, Russo J, McCarty CA, Rockhill C, McCauley E, Richards J, Grossman DC. Depressive symptoms in adolescence: The association with multiple health risk behaviors. Gen Hosp Psychiatry 2010;32:233-9.

46 Cohen S, Kamarck T, Mermelstein R. A global measure of perceived stress. J Health Soc Behav 1993;24:385-96.

47 Radloff LS. The CES-D scale: A self-report depression scale for research in the general population. Appl Psychol Meas 1977;1:385-401.

48 Vasilenko SA, Lanza ST. Predictors of multiple sexual partners from adolescence through young adulthood. J Adolesc Health 2014; doi: 10.1016/j.jadohealth.2013.12.025. Epub online ahead of print $2014 \mathrm{Feb} 20$.

49 Khan MR, Kaufman JS, Pence BW, Gaynes BN, Adimora AA, Weir SS, Miller WC. Depression, sexually transmitted infection, and sexual risk behavior among young adults in the United States. Arch Pediatr Adolesc Med 2009;163:644-52.

50 Brawner BM. Comparisons of substance abuse, high-risk sexual behavior and depressive symptoms among homeless youth with and without a history of foster care placement. Contemp Nurse 2012;42:178-86.

51 Sales JM, Smearman EL, Brody GH, Milhausen R, Philibert RA, Diclemente RJ. Factors associated with sexual arousal, sexual sensation seeking and sexual satisfaction among female African American adolescents. Sex Health 2013;10:512-21.

52 Silverman JG, Raj A, Mucci LA, Hathaway JE. Dating violence against adolescent girls and associated substance use, unhealthy weight control, sexual risk behavior, pregnancy, and suicidality. JAMA 2001;286:572-9.

53 Flynn HA, Walton MA, Chermack ST, Cunningham RM, Marcus SM. Brief detection and co-occurrence of violence, depression and alcohol risk in prenatal care settings. Arch Womens Ment Health 2007;10:155-61.

54 Fenton KA. Time for change: Rethinking and reframing sexual health in the United States. J Sex Med 2010;9:250-2.

55 Schalet A. Must we fear adolescent sexuality? Med Gen Med 2004;6:1-23. 